Asuntos de defensa, poder y cooperación en relaciones internacionales 

rev.relac.int.estrateg.segur.13(2):13-37,2018

\title{
Globalización y regionalización en la economía política internacional contemporánea: aportes para nuevas teorizaciones sobre las regiones fronterizas*
}

\author{
Raúl Bernal Meza**
}

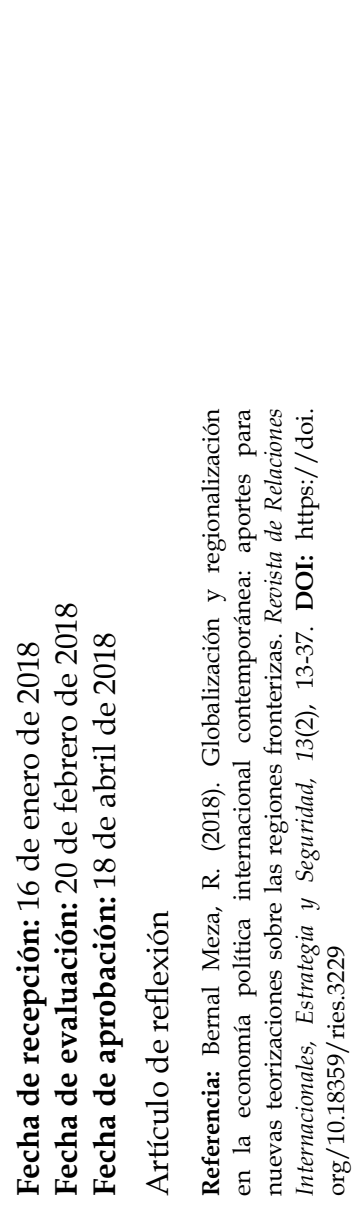

\section{Resumen}

Con excepción o en presencia de relaciones de conflicto entre Estados sudamericanos, las regiones fronterizas son consideradas áreas de intercambio, interconexión, integración y cooperación. Estas constituyen espacios de un tipo de regionalismo específico, el regionalismo fronterizo o regionalismo de fronteras, inscrito en el concepto más abarcador de regionalismo que, como tal, forma parte de los procesos contemporáneos que se dan en la economía política internacional. Con base en esta visión, el objetivo del artículo es aportar elementos analíticos y conceptuales para la teorización sobre esta moderna expresión del regionalismo. Se concluye que el regionalismo de integración fronteriza, en el caso de países en desarrollo, depende

* Investigación realizada en el Instituto de Estudios Internacionales (INTE) de la Universidad Arturo Prat de Chile, y preparada para el seminario internacional Hacia la Construcción de una Teoría de las Fronteras Latinoamericanas, desarrollado entre el 24 y 25 de enero de 2018.

** Doctor en Sociología, con estudios en I'Université de la Sorbonne Nouvelle y la Universidad Católica Argentina. Investigador y profesor del INTE y de la Universidad Nacional del Centro de la Provincia de Buenos Aires, y profesor de la Universidad de Buenos Aires. Correo electrónico: bernalmeza@hotmail.com 
también de dinámicas derivadas del carácter de economías extrovertidas, que forman parte de nuevos procesos y espacios de regionalización.

Palabras clave: economía; globalización; política internacional; regionalismo.

\title{
Globalization and Regionalization in Contemporary International Political Economy: Inputs for New Theorizing on Border Regions
}

\begin{abstract}
Except for or in the presence of conflicting relations among South American nations, border regions are considered areas of exchange, interconnection, integration and cooperation. These are spaces of a specific type of regionalism, border regionalism, attached to the broader concept of regionalism that, as such, is part of contemporary processes occurring in international political economy. The aim of this article is to provide analytical and conceptual elements to theorize on this modern expression of regionalism based on the conviction that there is no theorizing that explains or interprets all regionalisms. Current regionalisms entail qualitative and quantitative changes with respect to previous stages of the international political economy. Within this framework of bilateral or multilateral political relations linked by common non-militarized borders, border regionalism or cross-border regionalism has been influenced by three processes: 1) change in the nature and meaning of border; 2) processes of transnationalization and interdependence; and 3) changes in techno-productive patterns and international trade rules. It is concluded that border integration regionalism, in the case of developing countries, also depends on dynamics derived from the character of extroverted economies, which are part of new regionalization processes and spaces.
\end{abstract}

Keywords: economy; globalization; international politics; regionalism.

\section{Globalização e regionalização na economia política internacional contemporânea: aportes para novas teorizações sobre as regiões fronteiriças}

\section{Resumo}

Com exceção ou em presença de relações de conflito entre Estados sul-americanos, as regiões fronteiriças são consideradas áreas de intercâmbio, interconexão, integração e cooperação. Estas constituem espaços de um tipo de regionalismo específico, o regionalismo fronteiriço ou regionalismo de fronteiras, inscrito no 
conceito mais abarcador de regionalismo que, como tal, forma parte dos processos contemporâneos ocorridos na economia política internacional. Com base nesta visão, o objetivo do artigo é contribuir com elementos analíticos e conceituais para a teorização sobre esta moderna expressão do regionalismo. Conclui-se que o regionalismo de integração fronteiriça, no caso de países em desenvolvimento, depende também de dinâmicas derivadas do caráter de economias extrovertidas, que formam parte de novos processos e espaços de regionalização.

Palavras-chave: economia; globalização; política internacional; regionalismo.

\section{Introducción}

Las fronteras son espacios que limitan autonomías estatales, según la tradición que se remonta a los acuerdos de Westfalia. Pueden ser fuente de conflictos y percepciones de amena$z a, y$, de hecho, esta es la experiencia dominante en la historia. Pero las tendencias contemporáneas del sistema internacional, a partir de prácticas exitosas no solo en la Europa comunitaria, sino además en otros escenarios, como el Mercosur ${ }^{1} y$ lo que se ha rescatado como aporte en el caso de la Comunidad Andina de Naciones ${ }^{2}$, permiten la generación de dinámicas positivas que pueden derivar en prácticas de cooperación, integración o regionalismo más generalizadas, especialmente en Suramérica ${ }^{3}$.

Estas tres dinámicas —cooperación, integración y regionalismo- han teni- do distintos grados de desarrollo, según las áreas geográficas y los Estados comprometidos. A menudo, algunas de ellas son entendidas como sinónimos o prácticas semejantes, un error que debe subsanarse para entender las tendencias más actuales que desafían las prácticas políticas de los poderes (nacionales, estaduales, locales) y que, además, ponen en jaque su propia interpretación.

La revisión de la literatura especializada muestra que el significado de la cooperación no es claro. A veces esta puede ser vista por sus antítesis: la competencia, el aislamiento y la discordia (Bernal-Meza, 2000). Ella se configura en ese terreno intermedio, más o menos amplio, en el que el conflicto y la armonía se mezclan en diversas proporciones (Caporaso, 1987, p. 29). Para Keohane (1988, p. 50), la cooperación es la conducta orientada

1 Un excelente estudio sobre veinte años de funcionamiento del Mercosur, que compara la evolución de las políticas exteriores de sus miembros por impacto del proceso de integración, es el libro de Regina María Gadelha (2013).

2 Es muy interesante, al respecto, el excelente estudio de Germán Camilo Prieto (2016).

3 Desde distintas perspectivas, recomendamos cuatro textos que aportan aspectos analíticos e históricos sobre estas dinámicas de la economía política latinoamericana en la última década: Germán de la Reza (2006), Eduardo Pastrana y Hubert Gehring (2014), Noemí Mellado (2014) y Eduardo Pastrana (2015). 
a promover ventajas recíprocas entre países; un proceso a través del cual las políticas seguidas por los gobiernos llegan a ser consideradas por los asociados como acciones que facilitan sus propios objetivos, como resultado de la coordinación de políticas.

Para Caporaso (1987), la integración es una de las formas que adquiere la cooperación internacional, y existen tres teorías sobre esta: integración regional, interdependencia y formación de regímenes. En el escenario internacional donde se iniciaba el presente siglo, se interpretaba que la diferencia sustancial entre cooperación e integración era clara. Por medio de la primera se trata de reducir las barreras, para dar a las transacciones económicas una mayor flexibilidad; con la segunda se persigue la supresión absoluta de dichas barreras, para crear un mercado único, sin trabas fronterizas. Por ello, mientras que la cooperación es posible entre países que tienen distintos sistemas monetarios, fiscales, de seguridad social, y hasta poseen una visión completamente distinta de la organización de la empresa, la integración plena es factible cuando se ha llegado a una armonización muy profunda del marco institucional de la economía (Tamames, 1995, p. 48 y ss.; Bernal-Meza, 2000, p. 252).

La integración regional es un proceso progresivo de articulación de políticas públicas en el que convergen distintos actores que intentan, mediante mecanismos positivos y cordiales, de distinta naturaleza, crear espacios de coopera- ción con diversas características; crear espacios políticos, económicos y sociales que logren contribuir a incrementar el bienestar de los ciudadanos, mejorar las condiciones estructurales de desarrollo, optimizar la inserción internacional y ampliar la capacidad de negociación de las partes que impulsan dicho proceso. En tanto, los regionalismos representan procesos políticos de construcción de regiones que toman en consideración la integración regional en todas sus dimensiones, no solo la económica, y que pretenden la convergencia de elementos, formales e informales, que faciliten la construcción de espacios geopolíticos y cognitivos de representación de los diversos actores que los conforman. Con regularidad, integración y regionalismo se emplean como sinónimos; sin embargo, son dos conceptos claramente diferenciables (Ojeda, 2017).

La regionalización es [...] tanto el proceso de creación específica de un espacio común como el resultado de la puesta en marcha de la integración [...]. Aunque el énfasis se encuentra en los aspectos económicos $[\ldots]$, se debe reconocer que un proceso de regionalización no es puramente económico, sino simultáneamente político, social y cultural. (Bernal-Meza y Masera, 2008, p. 6)

Estas características se comenzaron a advertir cuando se observó la evolución del regionalismo y se distinguió entre uno viejo, como el que dio origen al proceso europeo de posguerra y al de 
cuño cepalino, de integración proteccionista, preocupado por el desarrollo económico, y el nuevo, que se diferencia del anterior en que no surge exclusivamente a partir de las consideraciones estatales, sino que deviene tanto de factores domésticos como globales. Esta forma de regionalización, dentro de la cual se puede encuadrar parcialmente a Suramérica, vincula lo doméstico, lo nacional y lo global (Pastrana, Betancourt y Simmonds, 2014, p. 92; Hettne y Söderbaum, 2008, p. 65).

Pastrana et ál. (2014) señalan que, según Väyrynen (2003), el nuevo regionalismo se compone de dos dimensiones relacionadas: primero, el proceso de transformación intrarregional; segundo, la definición de fronteras externas. El primero es lo que se llama propiamente regionalización (regionalization), que consiste en la aparición de un contexto en la región constituido por interdependencia económica, lazos institucionales, confianza política y sentido de pertenencia cultural, así como el tema ambiental y el de seguridad. El segundo puede conceptualizarse como regionalidad (regionness), entendida como un nivel de consolidación suficiente de la regionalización. Implica, por lo tanto, la existencia real de una espacialidad, una cooperación significativa y una identidad (Pastrana et ál., 2014).

La visión sobre la cual se desarrolla el presente trabajo supone que, con excepción o en presencia de relaciones de conflicto entre Estados sudamericanos, las regiones fronterizas deben ser consideradas como áreas de intercambio, interconexión, integración y cooperación, que constituyen espacios de un tipo de regionalismo específico, el regionalismo fronterizo o regionalismo de fronteras. Este último está inscrito en el concepto más abarcador de regionalismo —más amplio que el de integración-, y que como tal forma parte de los procesos contemporáneos que se dan en la economía política internacional.

Se considera que las fronteras no tienen actualmente la conceptualización que dominó las relaciones internacionales bilaterales o multilaterales del pasado, en la cual tales fronteras eran concebidas como áreas de riesgos y amenazas, zonas de alta seguridad de carácter político-militar, y, por tanto, analizadas bajo la predominante $-y$, en la mayoría de los casos, excluyente- interpretación del realismo y la geopolítica.

El objetivo de este artículo es aportar elementos analíticos y conceptuales para la teorización sobre esta moderna expresión del regionalismo, en el marco de la economía política internacional contemporánea, partiendo del convencimiento de que no hay una teorización que explique o interprete a todos los regionalismos (Bernal-Meza, 2015a). La razón es que el regionalismo (y la integración), en cada etapa sobre la cual se ha realizado el análisis en su momento histórico, ha estado influido por las dinámicas provenientes del sistema mundial, en el que esas expresiones están insertas y, por tanto, 
sensibles a los aspectos económicos, políticos y eidético-culturales del periodo histórico del sistema.

\section{La economía política contemporánea y el regionalismo}

En la fase contemporánea de las relaciones internacionales, los espacios integrados no pueden aislarse del estudio del orden mundial ni del fenómeno de la globalización (Gilpin, 2000, 2001; Bernal-Meza, 2000; Fawcet y Hurrell, 1993). Los regionalismos actuales suponen cambios cualitativos y cuantitativos respecto a etapas anteriores. El mundo contemporáneo ha sufrido enormes transformaciones en las últimas décadas. Entre ellas, podemos identificar cuatro principales: 1) la caída del bloque comunista de economías de planificación centralizada y el desmembramiento de la Unión Soviética, junto a la transición de estos países hacia una economía de mercado; 2) la unificación de la economía mundial en un contexto de fuertes asimetrías, donde conviven fuerzas centrífugas de dispersión, fragmentación y crisis, con fuerzas centrípetas de entrelazamiento e interdependencia (globalización/ mundialización); 3) la vigencia de un paradigma sociotecnológico (sociedad de la información) que incluye nuevos modelos de producción científico-tecnológicos, localizados en sistemas de innovación territoriales de alta especialización para la generación de tecnologías digitales, infraestructuras y redes de acceso universal; 4) una renovada tendencia a la formación de espacios regionales de comercio (regionaliza- ción), pero con agendas de discusión totalmente inéditas por la variedad de temas y el alcance de las negociaciones (Bayne y Woolcock, 2003, 2007; Gilpin, 2000, 2001; Fawcet y Hurrell, 1993; Hurrell, 1994; Bernal-Meza, 2009; Bernal-Meza y Masera, 2008; Tamames, 1995).

Así, la concepción del regionalismo ha ido evolucionando, según los cambios producidos en la economía y la política internacionales.

En el marco de relaciones políticas bilaterales o multilaterales vinculadas por fronteras comunes no militarizadas, el regionalismo fronterizo, regionalismo de fronteras o regionalismo transfronterizo ha sido influido por tres procesos, que son los que mayormente inciden en su dinámica reciente. Se exponen a continuación.

1. El cambio en la naturaleza y el significado del concepto de frontera, que transitó desde la visión de límite/división a aquella de integración y complementación. De esta manera, se abandonó la percepción de conflicto para avanzar hacia la concepción de integración y cooperación.

Los países se plantean la posibilidad de participar en un proceso de integración regional porque prevén que con esta agrupación pueden obtener mayores beneficios políticos y económicos que si continúan aislados. En este sentido, la percepción de que en un mundo globalizado las economías pueden ser 
más dinámicas y competitivas, con mayor poder de negociación y de inserción internacional si cooperan con otras, se relaciona con el aumento de la conciencia regional (Hurrell, 1994; Caporaso, 1987). Incluso en relaciones interestatales dominadas por el paradigma realista, las posibilidades que brindan los ejemplos de soft power, como la paradiplomacia, tienden a generar condiciones de mayor interdependencia de las sociedades involucradas, a través de vínculos más laxos o más informales que aquellos que se expresan por medio de los organismos y agencias estatales responsables de las relaciones internacionales del país (Bernal-Meza, 2015a).

2. Los procesos de transnacionalización e interdependencia, que han generado una extraordinaria profundización de los intercambios de todo tipo entre las sociedades nacionales (Keohane y Nye, 1977; Merle, 1976, 1995; Tomassini, 1984a, 1991; Gilpin, 2000, 2001; Bernal-Meza, 1994, 2000; Barbé, 1995).

La transnacionalización, desde la década de los sesenta, fue el elemento identificador del mundo occidental contemporáneo. La transnacionalización de la economía, por la acción internacional de las grandes empresas, corporaciones y bancos, con sede en Estados Unidos y otros principales países capitalistas, impulsó un proceso similar en otros segmentos de la realidad social: la cultura, la política, las formas de organización y representa- ción social del sistema internacional y en este, con lo cual el sistema social mundial capitalista absorbió una dinámica distinta a la que había identificado el periodo del aumento constante de la productividad junto al surgimiento de un sistema de Estados de carácter mundial (internacionalización), fenómenos que habían caracterizado el nacimiento del mundo moderno, entre finales del siglo XV y comienzos del XVI (Bernal-Meza, 2000; Ferrer, 1996). Como señaló Luciano Tomassini (1984b),

[...] la transición de un mundo configurado por las relaciones entre Estados soberanos a otro caracterizado por el fortalecimiento de las relaciones transnacionales entre los múltiples segmentos que presentan las distintas sociedades nacionales, constituye probablemente la tendencia central del sistema internacional contemporáneo. (p. 15)

El proceso de transnacionalización daba cuenta entonces de que el desarrollo de las economías capitalistas estaba experimentando profundas transformaciones que repercutían sobre el funcionamiento global de las formaciones sociales nacionales, a medida que estas ingresaban a la etapa de transnacionalización del capital. La concentración del capital, al desbordar las fronteras nacionales, impulsaba una reorganización de las condiciones internas y externas del funcionamiento de las sociedades capitalistas (BernalMeza, 2000, pp. 137-138; Trajtenbert y Vigorito, 1981). 
El proceso de transnacionalización incrementó la interdependencia entre las sociedades, y ambos fenómenos pasaron a caracterizar las décadas posteriores a los setenta y los ochenta.

Quizás la expresión que más identificaría el periodo sería la transición de un mundo configurado por las relaciones entre Estados soberanos a otro donde se fortalecerían y profundizarían las relaciones transnacionales entre segmentos distintos de las diversas sociedades que integraban el sistema mundial. Los cambios y las nuevas características que asumían las relaciones entre Estados, entre estos y las distintas sociedades nacionales, así como entre las sociedades nacionales mismas fueron marcando la agenda internacional con la introducción de nuevos temas. Estos daban cuenta de la sustitución de un mundo dominado por los imperativos de la seguridad y el poder militar por otro donde tenían también importancia asuntos que reflejaban intereses específicos de las sociedades $y$, a su vez, la creciente importancia que estaban teniendo los denominados actores no estatales en la política mundial (Bernal-Meza, 2000; Bayne y Woolcock, 2003, 2007).

La difusión de las visiones y prácticas de las comunidades originarias, los movimientos étnicos y la búsqueda de reconocimiento de sus derechos ancestrales, las autonomías subnacionales, la expansión de la paradiplomacia y hasta el surgimiento de los nuevos Estados plurinacionales - como Bolivia y Ecuador - son resultado de es- tas dinámicas que explosionaron y se expandieron al finalizar la Guerra Fría. Dado el número y la importancia de los actores que participan e impulsan el proceso de globalización, la tendencia es la aceleración del empuje del proceso: empresas transnacionales, corporaciones transnacionales, organismos y organizaciones internacionales, gobiernos, ONG, y movimientos sociales, étnicos, políticos y culturales. Las negociaciones internacionales de las distintas agendas (económicas, comerciales, medioambientales, de cooperación al desarrollo, etc.) actúan a favor de una creciente internacionalización, y, paralelamente, se asiste a la constante expansión de los procesos de integración a distintas escalas: regional, subregional, bilateral y fronteriza.

3. Los cambios en los patrones tecnoproductivos y las normas del comercio internacional, que pasaron de una lógica de comercio de bienes terminados, transados entre países, a un comercio de economías nacionales integradas por vía de las cadenas globales de valor (Kuwayama, 1992; Gullstrand y Olofsdotter, 2007; Bonaglia y Goldstein, 2007; Dymond y Hart 2008; Martins y Sato, 2012).

Las cadenas globales de valor identifican el mapa del comercio internacional que va sustituyendo a las formas que relacionaban mercados nacionales y modelo fordista de producción, y que están profundizando el proceso de globalización; es decir, transnacio- 
nalización, interdependencia (simétrica y asimétrica), difusión de imágenes, concepciones y modos de vida, acompañados de la homogeneización de pautas de consumo y divertimiento, junto al debilitamiento de las regulaciones y controles del Estado, etc. Se trata de una nueva geografía del comercio internacional, ligada al rápido avance de la globalización de los procesos productivos a través de las cadenas de valor globales (CVG). La emergencia de las CVG se hizo viable principalmente por los avances en las tecnologías de la información, por el declive en los costos de transporte y por el surgimiento de nuevas formas de organizar la producción, lo que hizo florecer conceptos como los de producción modular y manufactura flexible. Actualmente, la economía global se ha transformado en una "estructura caleidoscópica y altamente compleja", involucrando la fragmentación de procesos productivos y su reubicación geográfica a escala global (Dicken, 2003).

La desagregación y dispersión geográfica de la producción genera profundos impactos en el comercio internacional. La gama de productos y servicios que se comercializan internacionalmente se ha ampliado considerablemente, y esto ha acompañado al movimiento de capitales y las inversiones en tecnologías, que se han vuelto mucho más fluidos y dispersos de lo que eran anteriormente (Dymond y Hart, 2008). Esta dimensión del proceso de globalización eliminó virtualmente la tradicional noción de que en el comercio internacional se transan primordial- mente materias primas y productos acabados; pero también eliminó la concepción rígida de que solo los países comercializan de manera individual o colectiva entre sí.

Una de las características de la globalización, en la actual fase del capitalismo histórico, es la concentración (oligopólica principalmente) del capital. La acumulación de capital aumenta la producción de bienes intensivos en capital y disminuye la producción de productos de mano de obra intensiva. Los países de altos ingresos han mantenido sus posiciones en condiciones de gran abundancia de capital físico, mientras que la mayoría de los países periféricos mantienen posiciones en el comercio internacional con abundante oferta de productos intensivos en ventajas comparativas ligadas a la tierra, los recursos naturales y la mano de obra intensiva, es decir, no profesional. Solo un puñado de países de medianos ingresos tiene alrededor del $50 \%$ de Intra-industry Trade (IIT) en el comercio. La mayoría de los países de altos ingresos tienen más del $50 \%$ del IIT, en tanto que los países de medianos ingresos se encuentran en el rango que va del 25 al $50 \%$, y la mayor parte de los de bajos ingresos tienen menos del $25 \%$ en el total del comercio. Estas características del comercio están en consonancia con dos nociones: 1) la economía de un país se diversifica más a medida que aumenta el ingreso, y 2) existe un volumen mayor de comercio entre los países más ricos (Gullstrand y Olofsdotter; 2007). Pero dado que se requieren estudios más amplios 
que permitan identificar claramente el perfil de los intercambios comerciales que se dan en las regiones fronterizas de las que ahora nos ocupamos —Chile, Perú y Bolivia-, es necesario centrarse en las características estructurales de sus macroeconomías, es decir, del patrón productivo y de inserción nacional en el cual estas áreas nacionales están insertas.

Dado que el regionalismo sudamericano, en el cual se insertan las relaciones de integración fronteriza, corresponde a dinámicas impulsadas o desarrolladas por países con economías extrovertidas —según la teoría del deterioro de los términos de intercambio, modelizada por su autor, Raúl Prebisch, sobre el concepto de centro-periferia-, el factor central, clave, de esos regionalismos lo constituyen las dinámicas que provienen del centro de la economía-mundo capitalista (Ayza, Fichet y González, 1975; Sunkel, 1987).

La especialización primaria que caracteriza a las economías al sur de México ha conducido a un nuevo ciclo de relaciones centro-periferia con China (BernalMeza, 2017a, 2017b, 2016a, 2012a, 2012b; Pastrana y Gehring, 2017; Ortiz y Dussel, 2016; Sevares, 2015; Cepal, 2015; Oviedo, 2014, 2012a, 2012b; Guelar, 2013; Ellis, 2009).

La potencia asiática es actualmente el segundo socio comercial de América Latina y el Caribe, el primero de Chile
(Ministerio de Relaciones Exteriores, 2017) y Perú 4 (Ortiz y Dussel, 2016), así como el primer exportador para Bolivia (Instituto Boliviano de Comercio Exterior, 2016). Debemos tomar como variable importante el impacto que la relación con China tiene sobre los procesos de regionalismo en general y sobre la integración de fronteras en particular. Derivado de lo anterior, y como afirma Dussel (2016), resulta necesario realizar un examen sobre el desempeño comercial de las regiones - en este caso, de la subregión limítrofe del norte de Chile_- para evaluar los efectos que las características de las relaciones comerciales con China tienen sobre la posible integración o desintegración de esas regiones. Como afirma uno de los especialistas:

[...] el análisis de los respectivos documentos y bloques comerciales refleja que China, en efecto, ha trastocado, en los últimos quince años, en forma significativa, el proceso de integración comercial, ha afectado tanto los diferentes procesos de integración comercial —a diversos niveles-, como a sus principales socios comerciales, en particular a los miembros de los distintos bloques comerciales [...]. (Dussel, 2016, p. 11)

Por tanto, deberíamos esperar que esas tendencias también se reproduzcan sobre los escenarios regionales de frontera.

4 En relación con el comercio de Perú con China, véanse los sitios electrónicos de los diarios Atlas Media y El Peruano. 
¿Qué es lo contextualmente diferente del nuevo regionalismo, si se observa el regionalismo fronterizo entre Chile, Perú y Bolivia? Actualmente se trata no de una integración que, como en los tiempos del Grupo Andino y de la Comunidad Andina de Naciones, promueva la industrialización sustitutiva de importaciones (ISI), sino — particularmente en el caso de Chile- de estrategias de inserción cuyo modelo de crecimiento está enfocado al exterior y depende esencialmente de la demanda internacional. Pero este proceso se da en el marco de una economía "con un creciente proceso de transferencia de segmentos de las cadenas globales de valor a los territorios [...]; las nuevas formas de integración basadas en flujos de inversión extranjera directa y comercio" (Ortiz y Dussel, 2016, p. 16).

Paralelamente, el hecho de que China se haya convertido en la segunda fuente de inversión extranjera directa y que sus proyectos de infraestructura se vinculen con las estrategias chinas de comercio internacional (Pastrana y Gehring, 2017; Dussel, 2016; Sevares, 2015), restringe las opciones de desarrollo de la infraestructura transfronteriza. Dichas inversiones se relacionan con las políticas de inversión china de acuerdo con sus objetivos, destinados a vincular los mercados de producción en Suramérica con los mercados industriales de demanda en China. La inversión extranjera directa (IED) de china está concentrada en los sectores mineros y de hidrocarburos (Cepal, 2015).
Si bien Perú es el segundo receptor de inversión china en América Latina, el único proyecto de infraestructura que se conoce, está en etapa de estudio: el tren bioceánico Perú-Brasil, que uniría Bayóvar (Piura) y Açu (São João de Barra), para facilitar el transporte marítimo con Tianjin en China (Nueva Sociedad, 2015; El Peruano, 2015; La República, 2017). Por su parte, Bolivia concentra inversión china en proyectos de los cuales el principal se relaciona con el tramo boliviano del ferrocarril Bayóvar-Açu, y aunque hay propuestas (en etapas de preestudio) vinculadas con infraestructura aeroportuaria y de carreteras (Sputnik Mundo, 2016), el principal interés chino es la explotación de recursos naturales bolivianos (ICEX, 2015), con negocios millonarios y favorables a las empresas y bancos chinos (Plataforma Energética, s. f.). Respecto de Chile, el único proyecto que se conoce es el financiamiento para el túnel binacional que conectará la provincia argentina de San Juan con los puertos de la IV Región de Chile, mientras que la única propuesta presentada posteriormente es el cofinanciamiento de un tren rápido entre Santiago y Valparaíso (Emol, 2018).

Perú, Bolivia y Chile concentran las menores cifras de IED china en infraestructura en la región (Nueva Sociedad, 2015), y ninguna de ellas se relaciona con el área de regionalismo fronterizo que aquí analizamos; en otras palabras, ninguna inversión china en Chile, Perú o Bolivia contribuye directamente al desarrollo económico y de comunicación para este regionalismo de frontera. 


\section{Regionalismo: teoría y dinámicas}

En un estudio reciente señalábamos que la regionalización o el regionalismo constituyen un fenómeno cuya interpretación teórica no tiene un consenso en la comunidad política y tampoco en la científica. No hay abstracción o elaboración teórica que pueda abarcar todos los procesos en curso o que puedan ser inscritos en esta denominación. La explicación es que el término hace referencia a distintas concepciones y a procesos diferentes. En relaciones internacionales, hablar de regionalismo significa referirse, al menos, a tres cosas, no necesariamente coincidentes, aunque sí compatibles: 1) en relaciones políticas internacionales, significa tanto la creación o expansión de un subsistema, como la integración a este; 2) como economía política, regionalismo implica algún grado de integración económico-comercial al mundo o dentro de un área geográfica común —contigua o determinada-, y 3) en política exterior, puede hacer referencia a un paradigma que sostiene elementos de una determinada política externa de inserción, de carácter Estado-nacional, común o armonizada (Bernal-Meza, 2015a).

Regionalización o regionalismo, como economía política, implican algún grado de integración económico-comercial hacia un área geográfica o al mundo. Es también una visión de la política externa, a través de la cual se concibe una forma alternativa de inserción internacional y también puede conducir a la configuración de un subsistema internacional. Generalmente, el término remite a la existencia de grandes territorios fácilmente discernibles (África, Asia, Europa, América del Norte y del Sur). Más difícil es definir regiones heterogéneas y de límites poco claros, como el Caribe o Europa Central. De hecho, algunas visiones que acompañaron la concepción que tuvo sobre el hemisferio la política exterior del presidente Lula da Silva reavivaron la discusión en la política exterior latinoamericana acerca de si América Latina constituía —o no- - una región común (Bernal-Meza, 2016b, 2016c, 2015b; Bernal-Meza y Bizzozero, 2014).

Los distintos criterios para identificar regiones dan lugar a diferentes configuraciones regionales: 1) criterios geográficos (situación continental, subcontinental, archipiélago, etc.); 2) criterios militares/políticos (alianzas u orientaciones ideológicas); 3) criterios económicos (desarrollo económico), y 4) criterios transaccionales (volumen $y$ frecuencia de los intercambios). Pero pueden existir otros criterios: idioma, religión, cultura, densidad de población, el clima (Couloumbis y Wolfe, 1979) y también los nuevos regionalismos, como los de frontera.

La construcción de una región descansa en elementos comunes básicos, que facilitan la tarea de la integración:

1. Proximidad: a pesar de que las regiones son, a priori, comunidades más imaginadas que reales (Smouts, 
1997), es evidente que tienden a conformarse en territorios donde existen factores comunes previos, históricos, culturales o geográficos. Por ello no sería erróneo hablar de regiones naturales con una identidad propia, y con un peso tal para ser reconocidas como actores unitarios en el escenario internacional.

2. Valores fundamentales compartidos: la promoción de un sistema político, la búsqueda del desarrollo socioeconómico, la industrialización, el crecimiento económico redistributivo $y$, en términos de la Cepal, la transformación productiva regional con equidad, como en el pasado lo fue la industrialización sustitutiva de importaciones.

3. Estrategias de gobernanza común: amplios y complejos vínculos de participación, tanto de actores públicos como privados, en términos de acciones sociopolíticas conjuntas. Esto permite integrar programas y decisiones de gobierno junto a una adecuada participación de las comunidades (sociales, étnicas, políticas) y de los agentes socioeconómicos en una orientación abajo-arriba (bottom-up) y no solo arriba-abajo (top-down), lo que confiere legitimidad y credibilidad (Bernal-Meza, 2015a; Bernal-Meza y Masera, 2008).

Además de este entorno de carácter internacional, están aquellas experien- cias de carácter transfronterizo, que no se proyectan más allá de la relación y el vínculo entre dos o más países que comparten fronteras y la aplicación del concepto de región y regional al ámbito interno de los Estados. Navarrete (2006, p. 12), citando a Machado de Oliveira, señala que "a linha que divide um Estado de outro, a faixa que separa (ou une, mas não mistura) uma cultura de outra, conspira contra a organização compacta e isofórmica de território. A dimensão na vida da fronteira é bipolar e multiforme" (p. 379) En este sentido, la frontera es un límite que permanentemente debe ser transpuesto. La frontera es un espacio de rivalidad y convivencia, que articula esta separación simbólica en las manifestaciones de sus pobladores, de manera tal que termina produciéndose una especificidad propia, con su singularidad precisa (Bernal-Meza, 2015a). "Cada fronteira é uma fronteira", dice Navarrete.

De esta forma, nos referimos no solo a los mecanismos que permitieron, y posibilitan hoy, acciones bilaterales o multilaterales tendientes a la explotación de recursos naturales compartidos, sino además a la cooperación y complementación en áreas de frontera, caracterizadas por condiciones similares de aislamiento, lejanía respecto de los grandes centros políticoadministrativos de decisión, necesidad de autosuficiencia, ampliación de

\footnotetext{
5 "[...] la línea que divide un Estado de otro, el área que separa (o une, pero no mezcla) una cultura de otra, conspira contra la organización compacta y similar o parecida de territorio. La dimensión de la vida de frontera es bipolar y multiforme" (la traducción es mía).
} 
la base productiva, detención de la emigración interna hacia los grandes centros urbanos, necesidad de satisfacción de servicios (salud, educación, turismo protector de lo autóctono: sus comunidades, recursos naturales, áreas culturales de sus ancestros, etc.), situaciones deficitarias que pueden superarse gracias a la interrelación de aquellas economías dispersas, en dos o más países, con características geoeconómicas similares, y que por una vinculación favorecida por la cercanía de la frontera tienen posibilidades de complementarse, en bienes, recursos y servicios (Bernal-Meza,1986), como las que se dan en la frontera chilenoboliviana y chileno-peruana.

La experiencia de subregiones como la Cuenca del Plata muestra cómo la consideración de las zonas fronterizas —no como áreas finales de la capacidad de acción individual de los Estados, sino como polos dinámicos de cooperación y complementación fronteriza- resultó en un proceso que forjó la experiencia para modelos más profundos de integración, como es el Mercado Común del Sur (Mercosur). El hombre de la frontera es un agente de integración, aunque el tránsito fronterizo no sea legal ni regular (Bernal-Meza, 1986).

Sin embargo, ese hombre pertenece a comunidades sociales que desarrollan dinámicas de convivencia, comunicación e intercambios con otras comunidades que son reguladas por normativas y legislaciones nacionales distintas.
Baldersheim, Vegard y Ogard (2011) dan cuenta de la importancia que se le asigna en la Europa comunitaria a los actores políticos -locales o regionales - como agentes del desarrollo, y se refieren a las perspectivas sobre la probabilidad de que las relaciones de dependencia provocadas por la integración estimulen la generación de redes transfronterizas (Bernal-Meza, 2016b). Este podría ser el caso de una integración fronteriza entre Chile, Perú y Bolivia.

Como he señalado en otro estudio (Bernal-Meza, 2015b), tanto la acción de vinculación externa de las unidades subnacionales y de las regiones, como la paradiplomacia que ellas llevan a cabo desde hace décadas (Botto, 2010; Maira, 2010; Gasol e Iglesias, 2010; Aranda, Ovando y Corder, 2010; Ovando y González, 2014; Bernal-Meza, 2015a, 2016b; González, Cornago y Ovando, 2016) reflejan el cambio de las concepciones, de la teoría y la praxis, en relación con la visión estadocéntrica tradicionalmente dominante y la práctica real de las relaciones interfronterizas y transfronterizas que realizan los miembros de comunidades que comparten espacios de frontera.

Las vinculaciones societales a través de las fronteras han convalidado las presunciones del constructivismo. Este contribuye conceptual y analíticamente al análisis del papel que las identidades colectivas - en este caso, vinculadas por el tránsito fronterizo y la pertenencia a regiones comunes 
de frontera - tienen en el desarrollo de instancias transfronterizas comunes. Académicos como Hettne y Frederik (1998), Van Langenhove (2003) y Marchand, Bøås y Shaw (2016) son algunos de los que han desarrollado el denominado enfoque de nuevos regionalismos y que han teorizado sobre el rol de la identidad en el desenvolvimiento del regionalismo. Según Germán Prieto, que ha estudiado recientemente el fenómeno, los trabajos de estos autores "sugieren que el proceso de construcción de una región implica la configuración de una identidad colectiva que eventualmente podría motivar a los agentes a comprometerse con un proyecto regional y desarrollar instituciones regionales" (2016, p. 39). Si bien estos abordajes se explayan en general sobre espacios de territorios nacionales originalmente contiguos, el fenómeno transfronterizo o interfronterizo está implícitamente comprendido, pues este ha dado lugar a experiencias sobre las cuales han reflexionado autores como Philippart y Van Cutsem (1999), quienes señalan la relevancia del desafío que representa la proyección externa o internacional de las regiones para los enfoques realista y neorrealista, así como Baldersheim, Vegard y Ogard (2011), quienes han estudiado las potencialidades de la dependencia en la incidencia sobre la creación de redes transfronterizas.
La búsqueda de autonomía para relacionarse a través de la frontera se da, en alguna medida, en razón de los problemas que se presentan objetivamente en la vida de esas comunidades; sin embargo, como sugieren los análisis constructivistas, en la percepción del mundo también influyen los valores de los cuales están imbuidos los actores políticos y agentes económicos (Vigevani, 2004), y la manera como las comunidades puestas en relación comparten y proyectan su propia, y tal vez común, forma de interactuar e interrelacionarse. Rescatamos así el aporte que desde una visión constructivista puede significar el papel que desempeñan las ideas de las comunidades sociales y los líderes comunitarios e institucionales locales ${ }^{6}$ en el imaginario de la creación de un regionalismo de frontera. Las ideas, entendidas como "creencias de individuos" (Goldstein y Keohane, 2003), son variables que explican los resultados políticos.

\section{Integración y relaciones fronterizas}

El regionalismo surge como respuesta funcional a los problemas creados por los lazos de interdependencia asimétrica y vertical (por contener países de los hemisferios norte y sur), como sucede en el Nafta, en la relación entre Estados Unidos y México, pero que,

6 Se hace referencia a las ideas relacionadas con el regionalismo de frontera o la regionalización fronteriza entre Chile y Perú, y entre Chile y Bolivia, también imaginando una visión triestatal de intereses en áreas de frontera, como lo planteáramos en "Alternativas para una integración fronteriza entre Arica, Tacna y Oruro" (Bernal-Meza, 1986). 
utilizando el concepto de Ross (2005, 2012) de la doble asimetría ${ }^{7}$, puede aplicarse a las relaciones entre Chile y Perú, y Chile y Bolivia. Pero también el regionalismo surge por factores internos, propios de los países con relaciones vecinales, donde aquel, como dinámica, pone de relevancia los elementos comunes de las sociedades nacionales que participan de un área geográfica compartida, que pueden conducir a un esquema de integración y cooperación regional. Por ejemplo, la homogeneidad étnica y lingüística, la lejanía respecto de los centros políticos de decisión nacional y de los grandes mercados de producción, consumo y concentración de capital, así como la necesidad de enfrentar y resolver requerimientos vitales propios de la vida en comunidad son factores que refuerzan el sentido de identidad de una región fronteriza y que le permiten actuar como un actor unitario en la obtención de ciertas metas, y como una plataforma de promoción de intereses comunes.

La regionalización es el proceso de creación específica de un espacio común, así como el resultado de la puesta en marcha de la integración. El proceso supone, entre otros objetivos, poner en contacto economías relativamente homogéneas y con un nivel de desarrollo relativo comparable en la trayectoria de acoplamiento progresivo de las estructuras socioeconómicas; también, supone la convergencia política, a fin de crear instituciones comunes que permitan seguir, cuando sea necesario, una política coordinada en los ámbitos fiscales, financieros, industriales, comerciales, etc. Pero estos factores no siempre se encuentran a disposición de los actores sociales, económicos y culturales de las zonas de frontera, en especial cuando estas corresponden a espacios geográficos económicamente deprimidos o con ausencia de recursos naturales imprescindibles (agua, tierras cultivables, floresta, etc.). Aunque hoy el énfasis del regionalismo en general se encuentra en los aspectos económicos - por las razones previas que derivan de las dinámicas de una economía-mundo capitalista-, se debe reconocer que un proceso de regionalización no es puramente económico, sino simultánea y sistémicamente político, social y cultural (Bernal-Meza, 2000). Las regiones fronterizas son subsistemas abiertos, con comportamientos institucionales peculiares, con poca atención a la legalidad originaria, que desarrollan a cambio nuevas condiciones de relacionamiento e intercambios, pactadas explícita e implícitamente entre los actores locales. Sin embargo, no

\footnotetext{
7 Según la modelizacion aplicada a las relaciones internacionales de Chile (Ross, 2005, 2012), este país construyó en los últimos treinta años una doble asimetría: una hacia arriba, que lo vinculaba con las economías desarrolladas por vía de la apertura económica y cuyo principal instrumento de articulación han sido los acuerdos y tratados de libre comercio, y otra hacia abajo, que lo relaciona con los vecinos del norte, Peru y Bolivia, en la cual Chile aparece como el país fuerte, en una relación de interdependencia compleja con actores que se ubican en la periferia de la relación bilateral con Chile.
} 
pueden escapar a las lógicas de la inserción internacional de los territorios nacionales a los cuales administrativamente pertenecen. No obstante, como señalan Pastrana et ál. (2014), si bien hay un espacio que divide un adentro y un afuera, las fronteras no son necesariamente fijas, porque las identidades comunes o las interacciones de los actores domésticos se pueden transformar e ir, incluso, más allá de la vecindad geográfica.

\section{Conclusión}

La evolución del sistema mundial pone de manifiesto que las dinámicas de cooperación, integración y regionalización o regionalismo se han modificado según las tendencias que aquel impone sobre los contextos geográfico-económicos. El cambio en la naturaleza y el significado del concepto de frontera, los procesos de transnacionalización e interdependencia, y los cambios de los patrones tecnoproductivos y de las normas del comercio internacional inciden de manera sustancial sobre dichas dinámicas.

De manera específica, las características de la inserción económica internacional de los espacios Estado-nacional, de las cuales forman parte las zonas de frontera, también condicionan las características de los tipos y niveles de regionalismo. Entre ellos, se encuentra el que hemos denominado regiones fronterizas o regionalismo de frontera, tomando el caso de un área donde confluyen tres países en desarrollo, de los cuales dos no tienen relaciones diplomáticas entre sí.

Se puede argumentar que los siguientes aspectos nos ayudarán a teorizar de manera más específica sobre el fenómeno del regionalismo transfronterizo: la identificación del tipo de vínculos e interrelaciones que se dan en las áreas fronterizas que nos interesan aquí, de países sudamericanos; el conocimiento de la historia y la cultura que comparte el hombre de la frontera; las formas de articulación que vinculan a las sociedades y comunidades de un área geográfica común, y el conocimiento de las demandas y necesidades que los límites de frontera les impiden satisfacer a esas comunidades, al no estar bajo un régimen de cooperación reconocido.

Este último, al no estar bajo un régimen de cooperación reconocido que identifique las características de ese espacio geográfico, en un marco institucional hoy inexistente, en un futuro pudiera fomentar o influir sobre el diseño de políticas locales de desarrollo y cooperación.

Estas formas de regionalización o regionalismo, que hacen parte de los nuevos procesos y espacios de regionalización, son a menudo espontáneas. No todos los regionalismos de frontera o fronterizos requieren niveles similares de desarrollo, institucionalización o intervención de actores institucionales; tampoco es indispensable que todos avancen hacia la configuración de 
espacios comunes con similares grados de velocidad constitutiva, como se da en otras zonas geográficas de Suramérica, como las de la triple frontera entre Argentina, Brasil y Paraguay y otras áreas en el marco de la regionalización del Mercosur, o las de zonas geográficas bilaterales, como lo son aquellas que atraviesan las fronteras entre Colombia y Venezuela, Colombia, Brasil y Ecuador, y Chile, Perú y Bolivia ${ }^{8}$.

\section{Referencias}

Aranda, G., Ovando, C., y Corder, A. (2010). Experiencias paradiplomáticas en la región de Tarapacá y su proyección subregional. Estudios Internacionales, 42(165), p. 33-73.

Ayza, J., Fichet, G. y González, N. (1975). América Latina: integración económica y sustitución de importaciones. México, D. F.: Fondo de Cultura Económica, Naciones Unidas.

Baldersheim, H., Vegard H. y Ogard, M. (2011). The Rise of the Networking Region. Surrey: Ashgate Publishing Limited.

Barbé, E. (1995). Relaciones internacionales. Madrid: Tecnos.

Bayne, N. y Woolcock, S. (eds.) (2003). The New Economic Diplomacy. Aldershot: Ashgate Publishing Limited.

Bayne, N. y Woolcock, S. (eds.) (2007). The New Economic Diplomacy. Decision-making and Negotiation in In- ternational Economic Relations (2. ${ }^{\mathrm{a}}$ ed.). Aldershot: Ashgate Publishing Limited.

Bello, D. (2012). La triple frontera del Paraná (Paraguay-Brasil-Argentina). Santiago: RIL.

Bernal-Meza, R. (1986). Alternativas para una integración fronteriza entre Arica, Tacna y Oruro. Integración Latinoamericana, (118), 57-64.

Bernal-Meza, R. (1994). América Latina en la Economía Política Mundial. Buenos Aires: Grupo Editor Latinoamericano.

Bernal-Meza, R. (2000). Sistema mundial y Mercosur. Globalización, regionalismo y políticas exteriores comparadas. Buenos Aires: Grupo Editor Latinoamericano, Universidad Nacional del Centro de la Provincia de Buenos Aires.

Bernal-Meza, R. (2009). El regionalismo: conceptos, paradigmas y procesos en el sistema mundial contemporáneo. Revista Aportes para la Integración Latinoamericana, 15(21), 1-29.

Bernal-Meza, R. (2012a). China y la configuración del nuevo orden internacional: las relaciones China-Mercosur y Chile. En R. Bernal-Meza y S. Quintanar (eds.), Regionalismo y orden mundial: Suramérica, Europa, China (pp. 55-114). Buenos Aires: Nuevohacer, Universidad Nacional del Centro.

8 Entre los diversos trabajos que aportan miradas recientes sobre estos temas, se recomiendan los siguientes: Bello Arellano (2012), Pastrana y Jost (2012), Tapia Ladino y González Gil (2014.) y González, Cornago y Ovando (2016). 
Bernal-Meza, R. (2012b). China-Mercosur and Chile Relations. En L. Xing y S. F. Christensen (eds.), The Rise of China. The Impact on SemiPeriphery and Periphery Countries (pp. 59-102). Alborg: Aalborg University Press.

Bernal-Meza, R. (2015a). La inserción internacional de Brasil: el papel de Brics y de la región. Universum, 30(2), 17-35.

Bernal-Meza, R. (2015b). Paradiplomacia y regionalismo en situación de relaciones políticas en conflicto: el caso de Chile y Bolivia. Revista de Ciencia Política, 35(3), 605-627.

Bernal-Meza, R. (2016a). China and Latin America Relations: The WinWin Rhetoric. Journal of China and International Relations, (Special issue), 27-43.

Bernal-Meza, Raúl (2016b). Paradiplomacia, Autonomías y relaciones exteriores: nuevas perspectivas a partir del caso boliviano. En N. Cornago, S. González y C. Ovando (eds.), Relaciones transfronterizas y paradiplomacia en América Latina. Aspectos teóricos y estudio de casos (pp. 73-89). Santiago: RIL.

Bernal-Meza, R. (2016c). Integración cultural en América Latina: perspectivas, desafíos y viabilidad en el actual contexto mundial. En L. Weinberg (coord.), Historia Comparada de las Américas. Perspectivas de la integración cultural (pp. 53-79). México, D. F.: Centro de Investigaciones sobre América Lati- na y el Caribe (Cialc), Universidad Autónoma de México.

Bernal-Meza, R. (2017a). China en América Latina. Política exterior, discurso y fundamentos: diplomacia pública y percepciones en la región. En E. Pastrana Buelvas y $\mathrm{H}$. Gehring (eds.), La proyección de China en América Latina y el Caribe (pp. 171-187). Bogotá: Editorial Pontificia Universidad Javeriana y Konrad Adenauer Stiftung.

Bernal-Meza, R. (2017b). Las relaciones entre China y América Latina y la retórica 'ganadores-ganadores'. En Carlos Moneta y Sergio Cesarín (eds.), La tentación pragmática. China-Argentina/América Latina: Io actual, lo próximo y lo distante (pp. 25-51). Buenos Aires, Sáenz Peña: Editorial de la Universidad Nacional de Tres de Febrero.

Bernal-Meza, R. (2017c). Las relaciones internacionales de América Latina ante un cambio de época. En J. Á. Sotillo y B. Ayllón (coords.), Las transformaciones de América Latina (pp. 120-148). Madrid: Los Libros de la Catarata e Instituto Universitario de Desarrollo y Cooperación.

Bernal-Meza, R. y Bizzozero, L. (eds.) (2014). La política internacional de Brasil: de la región al mundo. Montevideo: Universidad de la República y Ediciones Cruz del Sur.

Bernal-Meza, R. y Masera, G. A. (2008). El retorno del regionalismo. Aspectos políticos y económicos en los procesos de integración internacional. Revista Aportes para la 
Integración Latinoamericana, (18), 1-18.

Bonaglia, F. y Goldstein, A. (2007). More than T-shirts: The integration of developing country producers in global value chains. Policy Insights, (49).

Botto, M. (2010). Integración regional y actores subnacionales. El caso del Mercosur. Temas y debates, (25), 83-106.

Bourdet Y., Gullstrand, J. y Olofsdotter K. (eds.) (2007). The European Union and Developing Countries. Cheltenham: Edward Elgar.

Caporaso, J. (1987). Enfoques teóricos sobre la cooperación internacional: el caso de América Latina. En M. Heraldo y F. Orrego Vicuña (comps.), La cooperación regional en América Latina. diagnóstico y proyecciones futuras (pp. 27-63). México, D. F.: El Colegio de México, Universidad de Chile.

Comisión Económica para América Latina y el Caribe (2015). América Latina y el Caribe y China. Hacia una nueva era de cooperación económica. Santiago: Naciones Unidas.

Couloumbis, T. A. y Wolfe, J. H. (1979). Introducción a las relaciones internacionales. Buenos Aires: Troquel.

De La Reza, G. (2006). Integración Económica en América Latina. México, D. F.: Universidad Autónoma Metropolitana, Plaza y Vandés.

Dicken, P. (2003). Global shift: Reshaping the Global Economic Map in the 21st Century (4. ${ }^{\text {a }}$ ed.). London: Sage.
Dussel, E. (coord.) (2016). La nueva relación comercial de América Latina y el Caribe con China. ¿Integración o desintegración regional? México, D. F.: Red Académica de América Latina y el Caribe sobre China, Universidad Nacional Autónoma de México, Unión de Universidades de América Latina y el Caribe y Centro de Estudios China-México.

Dymond, B. y Hart, M. (2008). Navigating New Trade Routes: The Rise of Value Chains, and the ChallengesforCanadian TradePolicy. Howe Institute Commentary. Recuperado de https://www.cdhowe.org/public-policy-research/ navigating-new-trade-routes-risevalue-chains-and-challenges-canadian-trade-policy

Ellis, R. E. (2009). China in Latin America. The Whats \& Wherefores. Boulder y Londres. Lynne Rienner Publishers, Inc.

Evo Morales anuncia millonarias inversiones de China en Bolivia. (enero de 2016). Sputnik Mundo. Recuperado de https:// mundo.sputniknews.com/ economia/201610061063937461bolivia-china-inversiones/

Fawcet, L. y Hurrell, A. (comps.) (1993). The New Regionalism and International Order. Oxford: Oxford University Press.

Ferrer, A. (1996). Historia de la globalización. México, D. F.: Fondo de Cultura Económica.

Fishlow, A. y Haggard, S. (1992). The United States and the Regionaliza- 
tion of the World Economy. París: Organización para la Cooperación y el Desarrollo Económicos.

Gadelha, R. M. (org.) (2013). Mercosul a Unasul. Avanços do processo de integração. São Paulo: Editorial da Pontificia Universidad Católica de São Paulo.

Gasol Varela, C. e Iglesias, E. (2010). El rol de los gobiernos subnacionales en los procesos de integración regional. Buenos Aires: Consejo Argentino para las Relaciones Internacionales (Cari), Centro Brasileiro de Relações Internacionais (Cebri).

Gilpin, R. (2000). The Challenge of Global Capitalism. The World ECOnomy in the 21st. Century. New Jersey: Princeton University Press.

Gilpin, R. (2001). Global Political Economy. Understanding the Internacional Economic Order. Princeton: Princeton University Press.

Goldstein, J. y Keohane, R. (2003). Ideas and Foreign Policy: An Analytical Framework. En J. Goldstein y R. Keohane (eds.), Ideas \& Foreign Policy. Beliefs, Institutions and Political Change (pp. 3-30). Ithaca: Cornell University Press.

González, S., Cornago, N. y Ovando, C. (2016). Relaciones transfronterizas y paradiplomacia en América Latina. Aspectos teóricos y estudio de casos. Santiago: RIL, Universidad Arturo Prat.

Gransow, B. Inversiones chinas en infraestructura: ¿una situación en la que todos ganan? (septiembre- octubre, 2015). Nueva Sociedad. Recuperado de http://nuso.org/ articulo/inversiones-chinas-en-infraestructura-una-situacion-en-laque-todos-ganan/

Guelar, D. (2013). La invasión silenciosa. El desembarco chino en América del Sur. Buenos Aires: Random House Mondadori S.A., Debate.

Gullstrand, J. y Olofsdotter, K. (2007). Trade and Specialisation: Changing Patterns in the 1990s En Bourdet Y., Gullstrand, J. y Olofsdotter K. (eds.), The European Union and Developing Countries (pp. 7-28). Cheltenham: Edward Elgar.

Hettne, B.yFrederik, S. (1998). TheNew Regionalism Approach. Politeia, 17(3), 6-21.

Hettne, B. y Frederik, S. (2000). Theorising the Rise of Regionness. New Political Economy, 5(3), 457-473.

Hettne, B. y Söderbaum, F. (2008). The Future of Regionalism: Old Divides, New Frontiers. En A. F. Cooper, C. Hughes y P. de Lombaerde (eds.), Regionalisation and Global Governance: The Taming of globalisation? (pp. 61-79). New York: Routledge.

Hurrell, A. (1994). Regionalismo en las Américas. En A. Lowenthal y G. Treverton (Comps.), América Latina en un Mundo Nuevo (pp. 199-226). México, D. F.: Fondo de Cultura Económica.

Instituto Español de Comercio Exterior (julio, 2015). Empresas chinas invierten en Bolivia atraídas por el crecimiento del país latinoame- 
ricano. Recuperado de https:// www.icex.es/icex/es/navegacionprincipal/todos-nuestros-servicios/ informacion-de-mercados/paises/ navegacion-principal/noticias/ NEW2015422404.html?idPais $=$ BO

Instituto Boliviano de Comercio Exterior (3 de marzo de 2016). Comercio exterior de Bolivia, enero de 2016. Recuperado de http:// ibce.org.bo/images/ibcecifras_documentos/CIFRAS-489-ComercioExterior-Bolivia-Enero-2016.pdf

Keohane, Robert O. (1988), Después de la hegemonía. Cooperación y discordia en la política económica mundial. Buenos Aires, Grupo Editor Latinoamericano.

Keohane, R. O. y Nye, J. (1977). Power and Interdependence. Boston: Little, Brown.

Kuwayama, M. (1992). América Latina y la internacionalización de la economía mundial. Revista de la CEPAL, (46), 9-32.

Machado de Oliveira, T. C. (2006). Topología das relações fronteiriças elementos para o debate teóricopráticos. En T. C. Machado de Oliveira (org.), Território sem limites. Estudos sobre fronteiras (pp. 377408). Campo Grande: Universidade Federal de Mato Grosso do Sul.

Maira, L. (ed.) (2010). La política internacional subnacional en América Latina. Buenos Aires: Ediciones del Zorzal.

Marchand, M.H., Bøås, M. y Shaw, T. M. (1999). The Political Economy of New Regionalisms. Third World Quaterley, 20(5), 897-910.

Martins Cesar, S. E. y Sato, E. (2012). A Rodada Doha, as mudanças no regime do comercio internacional e a política comercial brasileira. Revista Brasileira de Política Internacional, (1), 174-193.

Más del 35\% de la inversión minera en Perú es de China. (20 de febrero de 2017). La República. Recuperado de http://larepublica. pe/economia/1017146-mas-del35-de-la-inversion-minera-en-peru-es-de-china

Mellado, N. (Dir. y ed.) (2014). Regionalismo latinoamericano: dimensiones actuales. Córdoba: Lerner Editora.

Merle, M. (1976) Sociologie des relations internationales. París: Dalloz.

Merle, M. (1995). Las fuerzas transnacionales. En Sociología de las relaciones internacionales (pp. 410476). Madrid: Alianza.

Ministerio de Relaciones Exteriores de Chile (2017, mayo 8). Reporte trimestral enero-marzo 2017. Recuperado de https://www.direcon. gob.cl/estudio/reporte-trimestral-enero-marzo-2017/

Navarrete, M. (2006). Región fronteriza uruguayo-brasilera. Laboratorio social para la integración regional: cooperación e integración transfronteriza (tesis de grado, Universidad de la República, Montevideo).

Ortiz S. y Dussel E. (2016). La nueva relación comercial entre América 
Latina y el Caribe y China: ipromueve la integración o desintegración comercial? En E. Dussel Peters. (coord.), La nueva relación comercial de América Latina y el Caribe con China. ¿̇lntegración o desintegración regional? (pp. 13-58). México, D. F.: Red Académica de América Latina y el Caribe sobre China, Universidad Nacional Autónoma de México, Unión de Universidades de América Latina y el Caribe y Centro de Estudios China-México.

Ovando, C. y González, S. (2014). La relación bilateral chileno-boliviana a partir de las demandas tarapaqueñas: aproximación teórica desde la paradiplomacia como heterología. Estudios Internacionales, 46(177), 35-64.

Oviedo, E. (2014). Principales variables para el estudio de las relaciones entre Brasil y China. En R. Bernal-Meza y L. Bizzozero (eds.), La política internacional de Brasil: de la región al mundo (pp. 143-166). Montevideo: Cruz del Sur, Universidad de la República.

Oviedo, E. (2012a). The Struggle for Modernization and Sino-Latin American Economic Relations. En L. Xing y S. F. Christensen (eds.), The Rise of China. The Impact on SemiPeriphery and Periphery Countries (pp. 103-131). Aalborg: Aalborg University Press.

Oviedo, E. (2012b). Puja de modernizaciones y relaciones económicas chino-latinoamericanas en un mundo en crisis. En R. Bernal-Meza y S. Quintanar (eds.), Regionalismo y orden mundial: Suramérica, Europa, China. Buenos Aires: Nuevohacer, Universidad Nacional del Centro de la Provincia de Buenos Aires.

Pastrana, E. (2015). Problemas y desafíos contemporáneos de la gobernanza global y regional. Bogotá: Editorial Pontificia Universidad Javeriana.

Pastrana, E., Betancourt, R. y Simmonds, O. (2014). Regionalización, regionalidad y gobernanza multinivel en Suramérica. En E. Pastrana Buelvas y $\mathrm{H}$. Gehring (eds.), Suramérica en el escenario global: gobernanza multinivel y birregionalismo (pp. 85-123). Bogotá: Editorial Pontificia Universidad Javeriana.

Pastrana, E. y Gehring, H. (eds). (2014). Suramérica en el escenario global: gobernanza multinivel y birregionalismo. Bogotá: Editorial Pontificia Universidad Javeriana.

Pastrana, E. y Gehring, H. (eds.) (2017). La proyección de China en América Latina y el Caribe. Bogotá: Editorial Pontificia Universidad Javeriana.

Pastrana, E. y Jost, E. (eds.) (2012). Colombia y Ecuador: entre la integración y la fragmentación. Bogotá: Konrad Adenauer Stiftung.

Perú es segundo receptor de inversión china en AL. (24 de noviembre de 2015). El Peruano. Recuperado de http://www.elperuano.com.pe/ noticia-peru-es-segundo-receptorinversion-china-al-35801.aspx 
Philippart, É. y Van Cutsem, M. (1999). De l'explication à la prévision: analyse des perspectives en matière de relations internationales des régions d'Europe. Études Internationales, 30(4), 789-808. Recuperado de http://id.erudit.org/ iderudit/704090ar

Plataforma Energética (s. f.). Contratos millonarios, grandes consecuencias - Las empresas chinas en Bolivia. Recuperado de http://plataformaenergetica.org/node/38903

Prieto, G. C. (2016). Identidad colectiva e instituciones regionales en la Comunidad Andina. Un análisis constructivista. Bogotá: Editorial Pontificia Universidad Javeriana.

Rojas Aravena, F. (2013). Regionalismo e integración regional. En T. Legler, A. Santa Cruz y L. Zamudio González (eds.), Introducción a las relaciones internacionales: América Latina y la política global (pp. 158-171). México, D. F.: Oxford University Press.

Ross, C. (2005). Chile en la doble asimetría: ensayo sobre política internacional. Si Somos Americanos, 7(1), 109-139.

Ross, C. (2012). Los desafíos de la Política Exterior Chilena. En M. Artaza y C. Ross (eds.), (2012), La política exterior de Chile, 1990-2009 (pp. 853-880). Santiago: RIL.

Santiago-Valparaíso en 45 minutos? Presentan a Bachelet proyecto de tren de alta velocidad. (4 de enero de 2018). El Mercurio On-Line. Recuperado de http://www.emol.com/noticias/ Economia/2018/01/04/889864/ SantiagoValparaiso-en-45-minutosPresentan-a-Bachelet-proyecto-detren-de-alta-velocidad.html

Sevares, J. (2015). China. Un socio imperial para Argentina y América Latina. Buenos Aires: Edhasa.

Smouts, M.-C. (1997). La région comme nouvelle communauté imaginaire? En P. Le Gales y C. Lequesne (eds.), Les paradoxes des régions en Europe (pp.37-46). París: La Découverte.

Sunkel, O. (1987). Las relaciones centro-periferia y la transnacionalización. Pensamiento Iberoamericano. Revista de Economía Política, (11), 31-52.

Tamames, R. (1995). Estructura económica internacional. Madrid: Alianza.

Tomassini, L. (comp.) (1984a). Transnacionalización y desarrollo nacional en América Latina. Buenos Aires: Grupo Editor Latinoamericano.

Tomassini, L. (1984b). El proceso de transnacionalización y las relaciones externas de los países latinoamericanos. En L. Tomassini (comp.), Transnacionalización y Desarrollo Nacional en América Latina (pp. 15-65). Buenos Aires: Grupo Editor Latinoamericano.

Tomassini, L. (1991). La política internacional en un mundo postmoderno. Buenos Aires: Grupo Editor Latinoamericano, RIAL.

Tapia Ladino, M. y González Gil, A. (comps.) (2014). Regiones fronte- 
rizas. Migración y los desafíos para los Estados nacionales latinoamericanos. Santiago: RIL, Universidad Arturo Prat.

Trajtenbert, R. y Vigorito, R. (1981). Economía y política en la fase transnacional: algunos interrogantes. Santiago de Chile: Instituto Latinoamericano de Estudios Transnacionales (llet).

Tremolada, E. (ed.) (2014). Los procesos de integración como factor de paz. Bogotá: Universidad Externado de Colombia.

Tugores, J. (2004). Economía internacional. Globalización e integración regional. Madrid: McGraw-Hill.
Van Langenhove, L. (2003). Theorising Regionhood. UNU-CRIS e-Working Papers, W-2003/1. United Nations University - Comparative Regional Integration Studies. Recuperado de http://unpan1.un.org/intradoc/ groups/public/documents/nispacee/unpan015229.pdf

Väyrynen, R. (2003). Regionalism: Old and New. International Studies Review, 5(1), 25-51.

Vigevani, T. (2004). El marco jurídico e institucional para la gestión internacional de los actores subnacionales gubernamentales en Brasil. Integración \& Comercio, (21), 27-46. 
